\title{
Effect of Plating Parameters on the Electrodeposition of Ni-alumina Nanocomposite
}

\author{
Gobinda Gyawali", Dongjin Woo ${ }^{\mathrm{b}}$, Soo Wohn Lee \\ ${ }^{a}$ Department of Metallurgy and Materials Engineering, Sun Moon University, Asan, Korea \\ ${ }^{\mathrm{b}}$ Korea Institute of Construction Materials, Korea \\ 'Department of Environmental Engineering, Sun Moon University, Asan, Korea
}

(Received July 22, 2010 ; revised August 26, 2010 ; accepted August 30, 2010)

\begin{abstract}
$\mathrm{Ni}-\mathrm{Al}_{2} \mathrm{O}_{3}$ nanocomposite coatings were fabricated by conventional electrodeposition technique using nickel sulfamate bath. Effect of plating parameters on electrodeposition of $\mathrm{Ni}-\mathrm{Al}_{2} \mathrm{O}_{3}$ nanocomposite were studied. The properties of the nano composite were investigated by using SEM, XRD, and Vicker's microhardness test. The results demonstrated that $\mathrm{Al}_{2} \mathrm{O}_{3}$ incorporation in the composite coatings was found to be increased by increasing stir rate and $\mathrm{Al}_{2} \mathrm{O}_{3}$ content in plating bath. Microhardness of the composite coatings was also increased with increasing content of the nano particles in the plating bath. The surface morphologies of the nanocomposite coatings were found to be varied with varying $\mathrm{pH}$, current densities as well as alumina content in the plating bath.
\end{abstract}

Keywords: Composite coatings, Microhardness, Wear

\section{Introduction}

Codeposition of nano-sized hard ceramic particles like $\mathrm{SiC}, \mathrm{WC}$, diamond, $\mathrm{Al}_{2} \mathrm{O}_{3}, \mathrm{TiO}_{2}$, etc in metal matrix has been reported due to the superior properties of the composite over pure metal deposit ${ }^{1-5}$. The uniform dispersion of the second phase hard nano particles leads to the improvement in mechanical, tribological, corrosion resistance, anti-oxidation as well as microhardness in the composites. Nickels being an important engineering material, Ni-ceramic nano composite coatings are in wide demand on advance materials market. Ni-alumina composite coating is used primarily to increase the hardness, wear and corrosion resistance of the metal surfaces ${ }^{6-9}$. Although the Ni-alumina composite coatings have progressed tremendously, certain problems are still persistent in its fabrication. The volume percentage of alumina particles in coating is difficult to control quantitatively and the particles are frequently agglomerated together in the composite coating. The agglomeration of nano particles in coatings would impart poor mechanical properties in composite coatings ${ }^{10)}$. Hence, effective distribution of nano particles without agglomeration is the major concern of recent research.

To alleviate the agglomeration problem and to disperse the nano particles effectively in the metal matrix, various plating parameters like $\mathrm{pH}$, current density, stir rate, bath composition, temperature, use of surfactants etc. have to be determined to acquire reproducible readings. Hence, the first step of our investigation was to determine the effects of these parameters on the composite electrodeposition and to ensure that deposition is controllable as well as reproducible. In this paper, the effect of the plating parameters on the alumina incorporation and the corresponding change in composite properties were studied. Scanning Electron Microscope (SEM), Microhardness, X-Ray Diffraction (XRD), and Friction Wear analysis were conducted to characterize the prepared composite coatings.

*Corresponding author. E-mail : gbngyawali@gmail.com 


\section{Materials and Methods}

Electrodeposition process was carried out by conventional electroplating techniques in a $1000 \mathrm{ml}$ glass beaker. The plating electrolyte was made using nickel sulfamate of which concentration and compositions are listed in Table 1. Pure Ni-balls inside a titanium basket was used as anode while SUS304 stainless steel sheet of exposed area $2 \mathrm{~cm} \times 3 \mathrm{~cm}$ was used as cathode. Cathode was ultrasonically cleaned for 5 minutes before plating. The cathode and anode were placed vertically inside electrolyte and separated about $5 \mathrm{~cm}$ apart from each other. Direct Current (DC) was used for plating and the electrolyte was stirred using a magnetic stirrer.

After the electrodeposition, the samples were cleaned by running distilled water followed by ultrasonic cleaning for 5 minutes in order to remove loosely adsorbed particles and then subjected for further

Table 1. Bath composition and operating conditions

\begin{tabular}{|l|c|}
\hline $\mathrm{Ni}\left(\mathrm{NH}_{2} \mathrm{SO}_{3}\right)_{2}\left(\mathrm{~g} l^{-1}\right)$ & 300 \\
\hline $\mathrm{NiCl}_{2}\left(\mathrm{~g} l^{-1}\right)$ & 10 \\
\hline $\mathrm{H}_{3} \mathrm{BO}_{3}\left(\mathrm{~g} l^{-1}\right)$ & 40 \\
\hline$\alpha-\mathrm{Al}_{2} \mathrm{O}_{3}\left(\mathrm{~g} l^{-1}\right)$ & $5-20$ \\
\hline $\mathrm{Al}_{2} \mathrm{O}_{3}$ size $(\mathrm{nm})$ & 290 \\
\hline Sod.dodecyl sulfate $(\mathrm{mol} / l)$ & $1.4 \times 10^{-3}$ \\
\hline Temperature $\left({ }^{\circ} \mathrm{C}\right)$ & 50 \\
\hline $\mathrm{pH}$ & $2-5$ \\
\hline Current type & DC \\
\hline Current density $\left(\mathrm{mA} / \mathrm{cm}^{2}\right)$ & $20-120$ \\
\hline Stirring rate $(\mathrm{rpm})$ & $100-600$ \\
\hline
\end{tabular}

analysis. SEM (JSM-6400), XRD, and Microhardness of the composite coatings were analyzed. Microhardness was measured using Vickers microhardness tester (Buehler Ltd. USA), applying $0.98 \mathrm{~N}$ load for 10 seconds on ten different places of each sample crosssection and it were averaged.

\section{Results and Discussion}

The SEM images of surface morphology of the composite coatings at different current densities are shown in Fig. 1. The surface shows gradual smoothness on increasing current density. This might be due to the grain refining effect on increasing current densities ${ }^{4)}$. The surface morphology of composite coatings prepared at different electrolyte $\mathrm{pH}$ is shown in Fig. 2. At lower $\mathrm{pH}$, surface showed many cracks as well as larger grains. This pitting problem is due to the hydrogen embrittlements despite of using surfactants at lower $\mathrm{pH}$.

SEM image of the cross-section of Ni-alumina composite coatings having different alumina contents in plating bath is shown in Fig. 3. Increasing the alumina content in plating bath has increased the codeposition percent of alumina in nickel matrix as expected. The composite coatings were prepared by adding upto $20 \mathrm{~g} / \mathrm{l}$ of alumina nano powder in plating bath. Previous literatures also suggested that the increased content of nano particles in plating bath greater than $20 \mathrm{~g} / l$ has shown the decreased effective availability of nano particles to codeposit. This might be due to the more chance of agglomeration of nano particles in plating solution.

The effect of electrolyte movement on codeposition
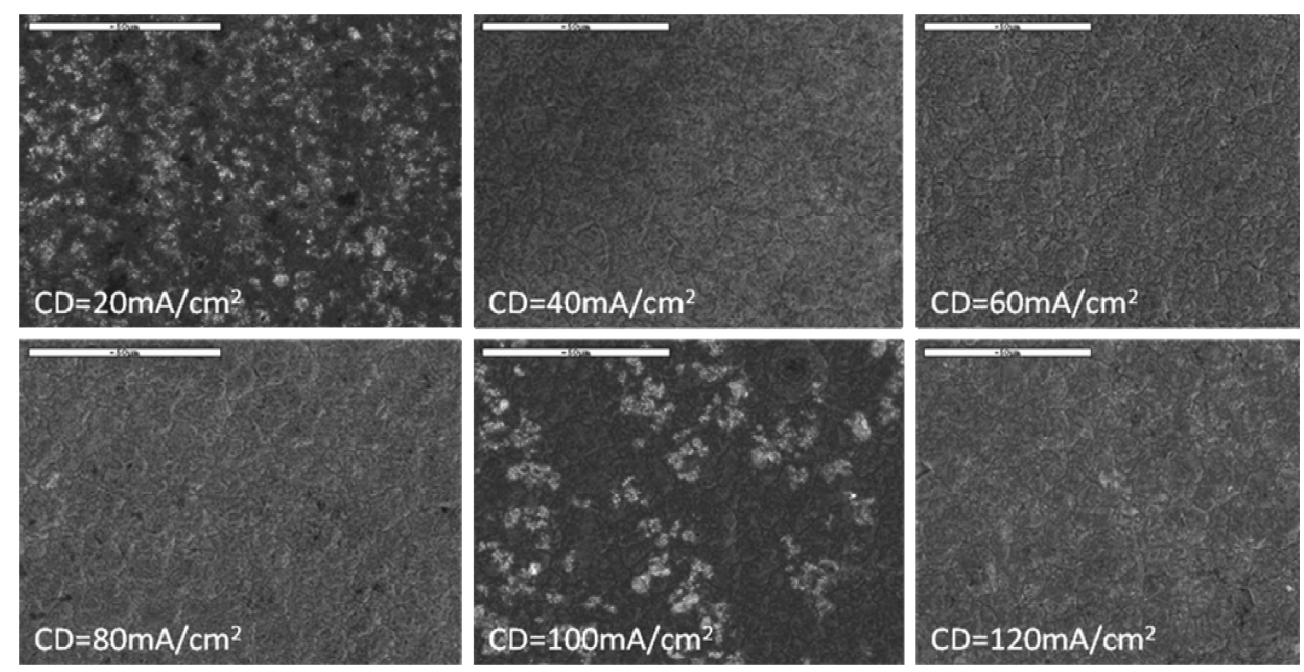

Fig. 1. Variation of Surface morphology of Ni-alumina composites at different current densities (alumina content: $20 \mathrm{~g} / \mathrm{l}$, $\mathrm{pH}=4$, Temp. $\left.50^{\circ} \mathrm{C}\right)$. 


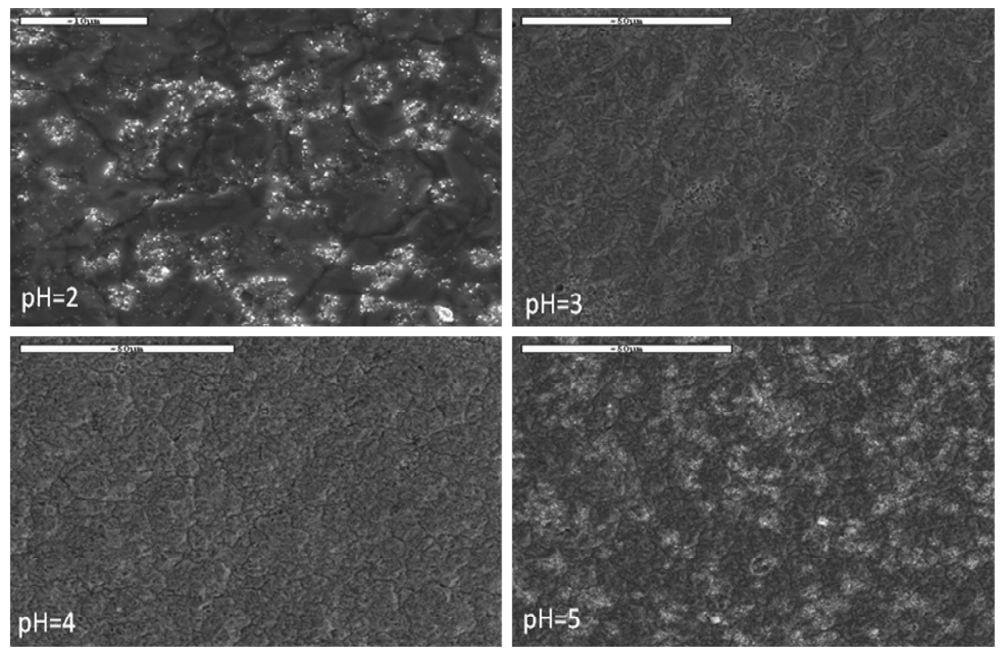

Fig. 2. Surface morphologies of Ni-alumina composites prepared at different $\mathrm{pH}$ (Temp. $50^{\circ} \mathrm{C}, \mathrm{SiC}=20 \mathrm{~g} / \mathrm{l}$, current density $=80 \mathrm{~mA} / \mathrm{cm}^{2}$ ).

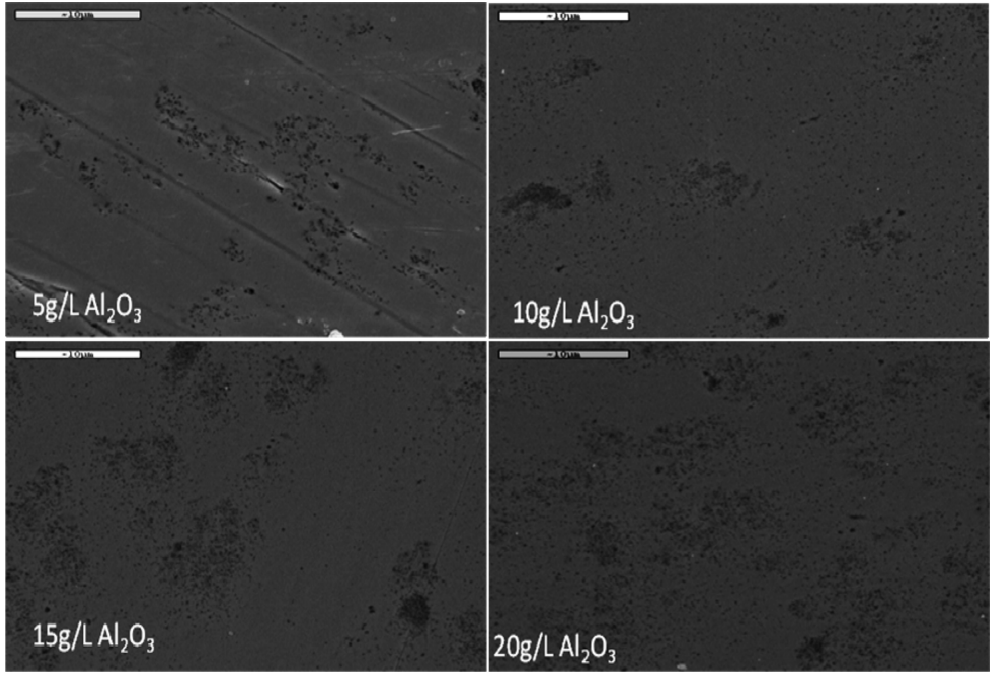

Fig. 3. Cross-section of Ni-Alumina composite coatings with different alumina content in plating bath; $\mathrm{pH} 4$, current density $80 \mathrm{~mA} / \mathrm{cm}^{2}$.
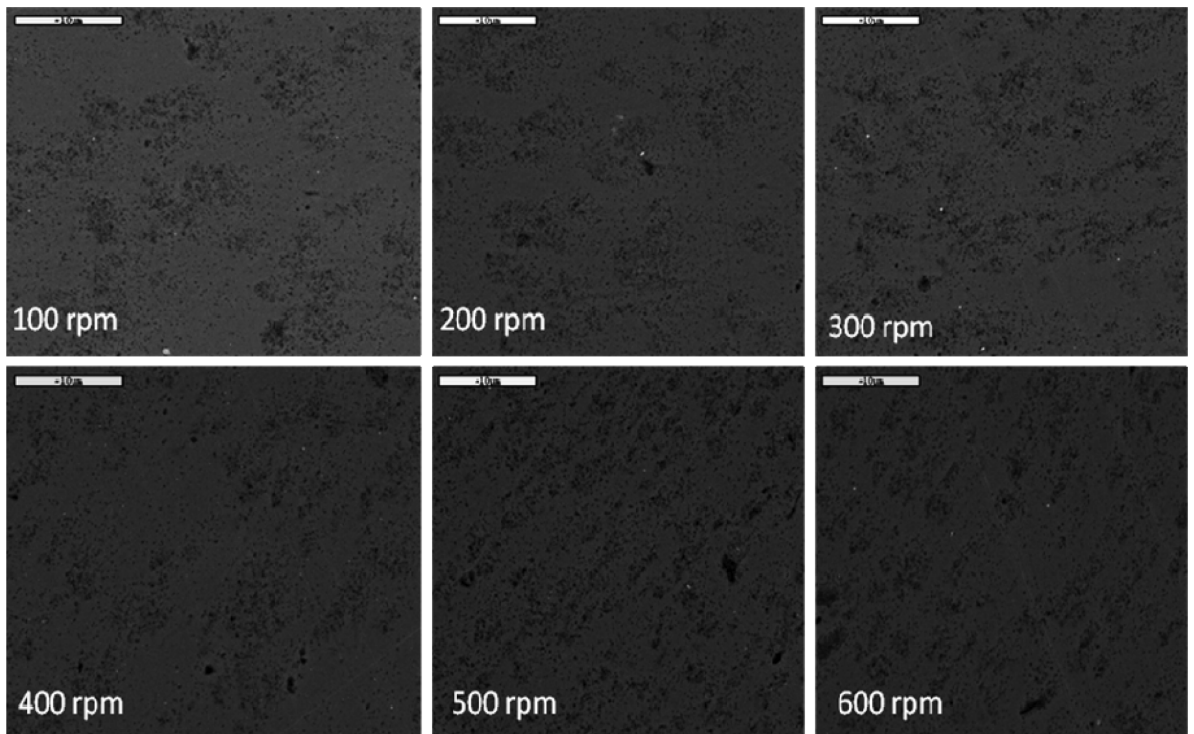

Fig. 4. SEM Cross-section images of Ni-alumina composite coatings with different stirring rate for $20 \mathrm{~g} / /$ alumina content in plating bath. 
of nano alumina particles was also studied. The cross-section of the samples at different stirring rate

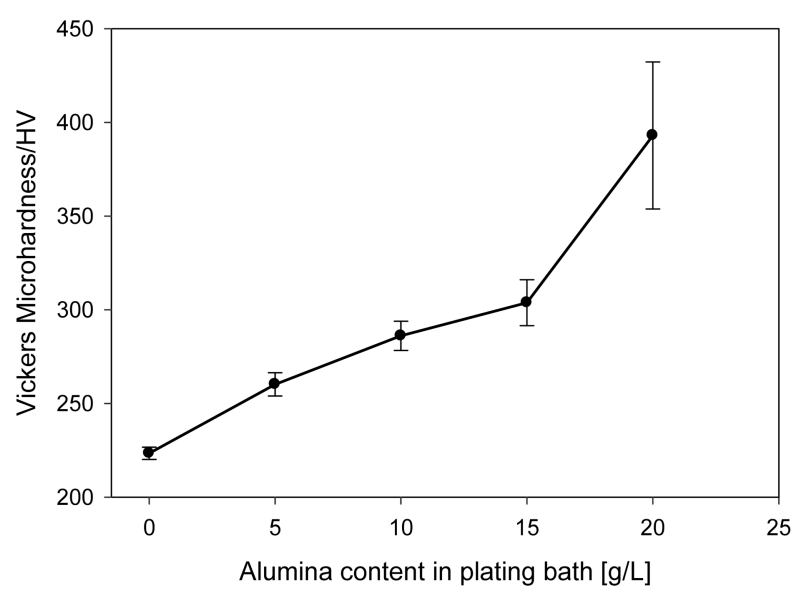

Fig. 5. Vickers Microhardness of Ni-alumina composite coating with different content of alumina in plating bath.

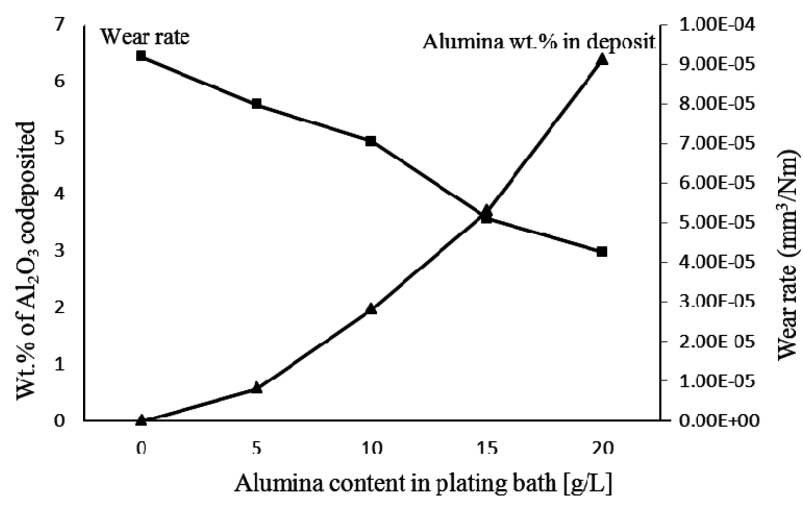

Fig. 6. Variation of wear rate and wt.\% of alumina in composite coating with different contents of alumina in plating bath. for $20 \mathrm{~g} / \mathrm{l}$ alumina in plating bath is shown in Fig. 4. It shows that increasing stirring rate has positive effect on homogeneously codeposition of nano particles in metal matrix. It is due to increasing the effective particles to be codeposited and restricting to the chance of agglomeration. Stirring rates above $300 \mathrm{rpm}$ have shown better dispersion and codeposition percentage of alumina nano particles.

The Vickers microhardness of the Ni-alumina composite coating was found to be increased by increasing the alumina content in the plating bath. The microhardness of coating obtained by $20 \mathrm{~g} / \mathrm{l}$ of alumina content in plating has shown nearly twice than pure nickel matrix as shown in Fig. 5. This increase in microhardness is attributed due to dispersion strengthening of nano particles as well as grain refining effect by the incorporation of alumina in metal matrix. The codeposition wt.\% of alumina and wear rate of composite coatings with respect to different content of alumina in plating bath is shown in Fig. 6. This shows the gradual increment in codeposition of alumina in coatings with increasing alumina content in plating bath. About 6.38 wt.\% alumina was successfully codeposited in nickel matrix for $20 \mathrm{~g} / \mathrm{l}$ alumina in plating bath. The Wear rate of Ni-alumina composite was found to be decreased with increasing alumina content in plating bath. The Wear rate of Ni-alumina composite is about half than that of pure nickel coating.

Wear tracks of pure nickel and composite coatings are shown in Fig. 7. Wear track of pure nickel shows more plastic deformations as compared to composite coatings.
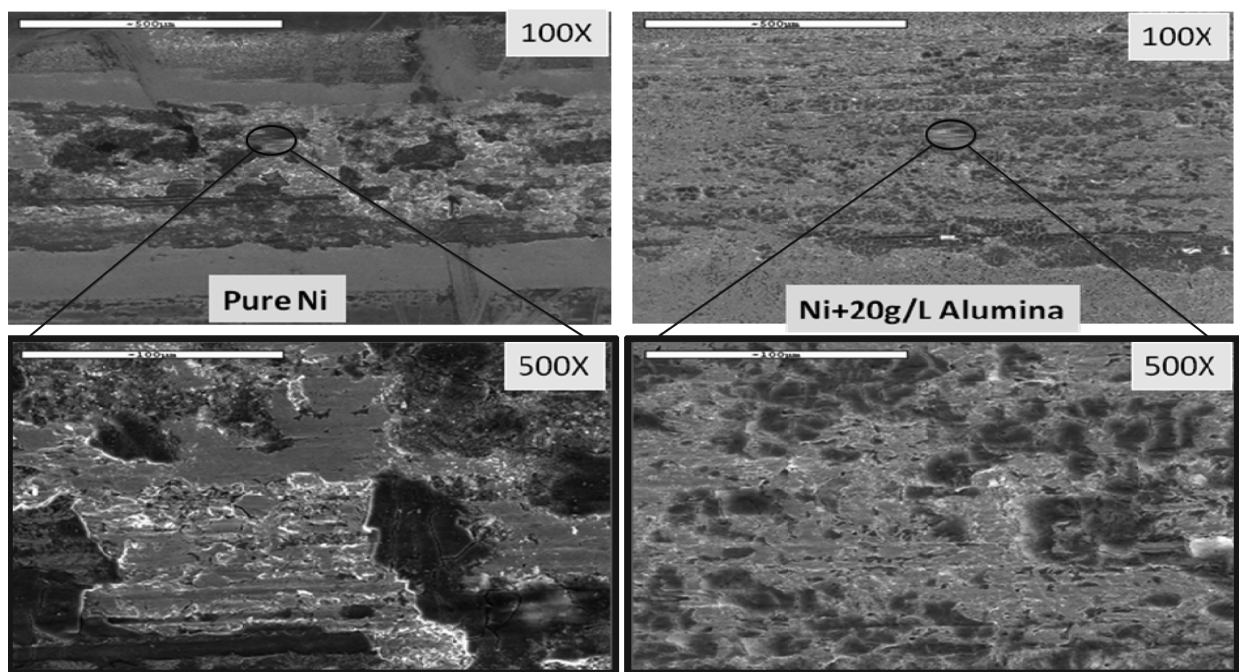

Fig. 7. Wear tracks of pure Nickel and Ni-alumina $(20 \mathrm{~g} / /)$ composite coatings (Load $2 \mathrm{~N}$, Freq. $10 \mathrm{~Hz}$, Time $10 \mathrm{~min}$., Counter ball SN1010C, No lubricants, Temp $23^{\circ} \mathrm{C}$, humidity $47 \%$ ). 


\section{Conclusions}

Ni-alumina composite coatings were prepared by conventional electrodeposition techniques using $\mathrm{Ni}$ sulfamate bath. Increasing the alumina content in plating bath (upto $20 \mathrm{~g} / l$ ) increased the co-deposition percentage of alumina in the deposit. Consequently, increase in Vickers microhardness was also measured. Homo geneously dispersed alumina particles were observed in coatings prepared at electrolyte stirring rate above $300 \mathrm{rpm}$. Optimum $\mathrm{pH}$ for electrodeposition was found to be around 4. Alumina particles were successfully codeposited upto 6.38 $\mathrm{wt} \%$ in composite coatings using sodium dodecyl sulfate as surfactant with optimized plating parameters.

\section{Acknowledgement}

This research was supported by Ministry of Knowledged Economy, Korea (Grant: Korea evaluation institute of industrial technology; 10033293).

\section{References}

1. M. R. Vaezi, S. K. Sadrnezhaad, L. Nikzad, Colloids and Surfaces A: Physicochem. Eng. Aspects 315 (2008) 176.

2. M. Stroumbouli, P. Gyftou, E. A. Pavlatou, N. Spyrellis, Surf. Coat. Technol. 195 (2005) 325.

3. L. Wang, Y. Gao, Q. Xue, H. Liu, T. Xu, Mater. Sci. Eng. A 390 (2005) 313.

4. H. Gul, F. Kilıc, S. Aslan, A. Alp, H. Akbulut, Wear 267 (2009) 976.

5. S. A. Lajevardi, T. Shahrabi, Appl. Surf. Sci. 256 (2010) 6775.

6. S. L. Kuo, Y. C. Chenb, M. D. Ger, W. H. Hwu, Mater. Chem. Phys. 86 (2004) 5.

7. Q. Feng, T. Li, H. Yue, K. Qi, F. Bai, J. Jin, Appl. Surf. Sci. 254 (2008) 2262.

8. N. S. Qu, K. C. Chan, D. Zhu, Scripta Materialia 50 (2004) 1131.

9. B. Szczygieł, M. Kołodziej, Electrochimica Acta 50 (2005) 4188.

10. A. F. Zimmerman, G. Palumbo, K. T. Aust, U. Erb, Mater. Sci. Eng. A328 (2002) 137. 